\title{
Alcohol during pregnancy and lactation: recommendations versus real intake
}

by

\author{
Guelinckx I ${ }^{1}$, Devlieger $R^{2}$, Vansant $G^{1}$
}

\begin{abstract}
Introduction

Even though total abstinence of alcohol for pregnant and lactating women is recommended, consumption prevalences ranging from $12 \%$ up to $30 \%$ have been reported. No Belgian data on alcohol consumption in pregnant women were recently published.
\end{abstract}

\section{Methods}

First, a literature search on the effects of alcohol consumption during pregnancy and lactation was performed in the MEDLINE database using Pubmed. Secondly, in a prospective study the alcohol consumption of 215 Belgian women was evaluated every trimester through 7-day food records. The international standard unit for alcohol or 1 standard glass equals $13.5 \mathrm{~g}$ pure ethanol. Binge drinking was defined as drinking more than $50 \mathrm{~g}$ on one occasion.

Results

Prenatal exposure of the foetus to alcohol can lead to a broad range of anomalies, including pre- and postnatal growth retardation, preterm delivery, central or craniofacial dysmorphia, neurological and behavioural disorders and disorders of cognitive function, which can persist throughout adulthood. In the Belgian study population, total abstinence of alcohol was seen in $76 \%$ of the women. Of the $24 \%$ of women who consumed alcohol, $13.9 \%$ consumed alcohol during 1 of the 3 weeks. These women were considered to be low consumers. Five women (2.5\%) reported drinking during all 3 weeks of recording. This could suggest that these women drink more regularly. No binge drinking was recorded. The maximum amount was 5 consumptions per week.

Conclusion

Even though total abstinence of alcohol for pregnant and lactating women is recommended, at least $25 \%$ of pregnant women still consumes alcohol. Health care providers have to be aware of the underreporting of alcohol use by pregnant women, especially if they drink heavily since they fear of being stigmatised.

\footnotetext{
1 Catholic University Leuven, Department of Nutrition-Public Health Medicine, Belgium

2 University Hospital Gasthuisberg, Department of Obstetrics and Gynaecology, Belgium isabelle.guelinckx@med.kuleuven.be
} 


\section{Introduction}

Alcohol is a widely accepted social drug: according to the 2004 Belgian Health Interview Survey $84 \%$ of the population older than 15 years consumes alcohol (1). Nine percent of Belgian women report that they consume at least once a month an amount of 6 or more units in one day. Daily alcohol consumption is present in 6\% of women (aged 15 years and older)(1). These daily users consume on average 2.1 glasses a day during weekdays and 2.7 glasses during weekend days (1). In this national survey problematic drinking was assessed using the CAGE questionnaire, a 4-item self-report screening test designed to detect alcohol addiction (2). Problematic drinking is diagnosed in $8.9 \%$ of women aged 25 to 44 (1).

Alcohol consumption during pregnancy is associated with well-known harmful effects (3). During lactation, alcohol use can also be harmful for the baby, even though popular beliefs suggests that alcohol consumption (especially beer) by a lactating woman improves milk production and, in turn, the nutrition of her infant.

Despite efforts to educate the public, the prevalence of alcohol use during pregnancy did not change substantially over the past years: in 1991, $12.4 \%$ of pregnant women in the United States consumed alcohol, while the prevalence decreased to $10.1 \%$ in 2002 (4). However, the average percentage of any alcohol use among pregnant women increased again to $12.2 \%$ (range: $10.2 \%-16.2 \%$ ) in 2005 , while the average percentage for binge drinking was $1.9 \%$ (range: $0.7 \%-2.9 \%$ ) in 2005 (5). In both these publications of the Center for Disease Control, any alcohol use was defined as having at least one drink over the past 30 days, and binge drinking as having 5 or more drinks on one occasion at least once in the past 30 days $(4,5)$. These American figures are low compared to other countries. O'Leary et al. found that only $41 \%$ of Australian women abstained from alcohol throughout pregnancy. One third consumed before and during pregnancy a low level of alcohol, meaning less than $60 \mathrm{~g}$ per week ( $<4.5$ glasses/week) and not more than $20 \mathrm{~g}$ in one day. There was a marked reduction at higher levels of consumption with percentage of heavily drinking women and binge drinking dropping from about $10 \%$ to $3 \%$ between the prepregnancy period and the first trimester (6). Thirty percent of the Swedish pregnant women in the study of Göransson reported to consume alcohol. A majority (23\%) reported a consumption frequency of once/month or less, but $6 \%$ reported alcohol use 2 to 4 times/month. None reported an amount of more than two standard drinks on the same occasion during their pregnancy (7). However, in a very recent, large study in the Avon area in England, $9 \%$ (589 in 6563) of pregnant women reported daily drinking in their second or third trimester and 24\% (1981 in 8240) consumed 4 drinks in one day at least on 1 occasion during pregnancy (8). To our knowledge, no recent Belgian data on alcohol consumption in pregnant women were published.

The aims of this study are to present a brief overview of the metabolism of ethanol, to describe the risks associated with in utero alcohol exposure and during lactation and finally to report the prevalence of alcohol use among Belgian pregnant women. 


\section{Methodology}

In this report 'alcohol' refers to ethanol $\left[\mathrm{CH}_{3}-\mathrm{CH}_{2} \mathrm{OH}\right]$, present in all alcoholic beverages (Table 1). The international standard unit for alcohol or 1 standard glass equals $13.5 \mathrm{~g}$ pure ethanol (9).

Table 1. Alcohol content for the most common alcoholic drinks

\begin{tabular}{|c|c|c|c|}
\hline Consumption & $\begin{array}{l}\text { Portion of } 1 \text { consumption } \\
\text { (g/glass) }\end{array}$ & $\begin{array}{l}\text { Alcohol by volume } \\
(\%)\end{array}$ & $\begin{array}{l}\text { Alcohol content } \\
\text { (g/consumption) }\end{array}$ \\
\hline Low-alcohol beer & 250 & $0-4$ & $0-10$ \\
\hline Alcopops & 275 & $5-8$ & $13.75-22$ \\
\hline Beer & $\begin{array}{l}250 \\
330\end{array}$ & $\begin{array}{l}4-12 \\
\text { (most often 4-6) }\end{array}$ & $\begin{array}{l}10-30 \\
13.2-39.6\end{array}$ \\
\hline Wine & 125 & $\begin{array}{l}\text { 9-18 } \\
\text { (most often 12.5-14.5) }\end{array}$ & $11.25-22.5$ \\
\hline Champagne & 100 & $10-13$ & $10-13$ \\
\hline Liquor & 35 & $15-55$ & $5.25-19.25$ \\
\hline $\begin{array}{l}\text { Spirits (e.g. whisky, gin, } \\
\text { vodka) }\end{array}$ & $\begin{array}{l}35 \\
50\end{array}$ & $\begin{array}{l}20-95 \\
\text { (usually around } 40 \text { ) }\end{array}$ & $\begin{array}{l}7-33.25 \\
10-47.5\end{array}$ \\
\hline
\end{tabular}

Based on information obtained from Nubel Food composition table and Oxford Handbook of Nutrition and Dietetics (36)

\section{Literature search}

Besides the report of the Belgian Superior Health Council (9), relevant publications were searched in the electronic database MEDLINE via PubMed and the reference lists of retrieved articles. The keywords used were: alcohol, alcohol consumption, pregnancy and lactation. The electronic databases were last searched on 1 August 2009.

Prospective study

The study was performed at the antenatal clinic, department of Obstetrics and Gynaecology, University Hospital of Leuven after approval by the Ethical Committee for Human Experiments of the Faculty of Medicine, Catholic University of Leuven. All pregnant women who attended antenatal care for the first time prior to 15 weeks of gestation between April 2007 and April 2008 were consecutively recruited. Exclusion criteria were: pre-existing diabetes or developing gestational diabetes (GDM), multiple pregnancy, recruitment after 15 weeks of gestational age, primary need for nutritional advice and inadequate knowledge of the Dutch language. Data on alcohol intake were obtained during each trimester of the pregnancy from 7-day dietary records. Participants were asked to record in as much detail as possible all foods and beverages including alcoholic drinks consumed over a 7-day period. One record was collected around week 10 of gestation, the second one around week 20 and the last one around week 32. The 7-day dietary records were processed with Becel Institute Nutrition Software 2005 (BINS). 


\section{Results}

\section{Alcohol metabolism during pregnancy}

Alcohol is absorbed in the stomach and jejunum and rapidly distributed throughout the body. It is transported to the liver where more than $80 \%$ is oxidated to acetaldehyde by the enzyme Alcohol Dehydrogenase (ADH) and subsequently converted to acetic acid by the enzyme Aldehyde Dehydrogenase (ALDH). In the next step, Acetyl-CoA is formed from Acetic Acid and can directly enter the Citric acid cycle (10). Acetic acid is a non-toxic metabolite, but acetaldehyde is highly unstable and forms free radicals which are highly toxic. During pregnancy, alcohol and its toxic metabolites can cross the placental barrier into the foetal bloodstream and amnionic fluid. The foetus can excrete alcohol through 3 different pathways: via placental clearance back to the maternal blood flow, oxidation by ADH and ALDH and urinary excretion into the amnionic fluid. The oxidative enzymes in the liver are present from the 2nd month but remain mostly inactive in the foetus. Excretion into the amnionic fluid creates the possibility of reuptake which is disadvantageous: the foetus swallows the amnionic fluid, alcohol is absorbed in the stomach and exposure to alcohol and the metabolites is prolonged. In contrast to acetaldehyde, alcohol is also present in breast milk in an equal concentration compared with maternal plasma (11). Alcohol is not stored in the breast tissue. Peak alcohol levels and clearance in the breast milk run parallel to the alcohol level in maternal bloodstream. Therefore the highest concentration is reached in most individuals one hour after drinking, however interindividual differences do exist (11).

Effects of in utero alcohol exposure and alcohol exposure during lactation

No exact dose-response relationship exists between the amount of alcohol consumed and the extent of damage to the infant. Drinking one or more glasses a day is associated with a nearly 5 -fold increase in the risk of a low birth weight (odds ratio(OR)=4.81) and a 2 -fold increase in the risk of preterm birth (adjusted $O R=2.51)(12)$. A reduced mental development index has been reported in children at the age of 1 that were exposed to more than $12 \mathrm{~g}$ ethanol/day (=1 glass/day)(9). At age 7, children who were prenatally exposed to 2 glasses of alcohol a day had a reduced IQ and learning problems (13). Alcohol use of this level can increase the incidence of miscarriage and foetal death (9). However, consumption of $5 \mathrm{~g}$ ethanol/day during pregnancy (=2-3 glasses/week) is already shown to alter neurological behavioir in 6-7-year-old children (9). The adjusted OR for 'moderate' consumption of three drinks per week for low birth weight was 2.6 and that for intrauterine growth retardation was 2.3 (14). Therefore alcohol use patterns within the social drinking range can have longlasting effects.

Some children who were exposed prenatally to alcohol have normal growth and physical development but display a typical pattern of behavioural or cognitive abnormalities, categorised as alcohol-related neurodevelopmental disorder (ARND). These abnormalities include neurological disorders such as impaired fine motor skills, vision and language, behavioural disorders such as ADHD, sleeping and feeding disorders, poor communication skills and dis- 
orders of cognitive function such as low intelligence quotient scores (IQ), visual-spatial inabilities and problems in memory, attention, or judgement $(9,15,16)$.

Chronic alcohol use of more than $90 \mathrm{~g}$ a day (=more than 6 units/day) can cause the foetal alcohol syndrome (FAS) (16). The Centers for Disease Control and Prevention in the US reports FAS in 0.3 to 1.5 per 1000 liveborn infants (17). The diagnosis is based on the presence of three criteria and associated symptoms: pre- and postnatal growth retardation, central nervous system abnormalities and craniofacial dysmorphia. This growth retardation can pursue during childhood, and catch-up growth is generally incomplete. Infants exposed prenatally to alcohol who are affected but do not meet the criteria for FAS are categorised as having suffered foetal alcohol effects (FAE) or alcohol-related birth defects. These include cardiac, skeletal, renal, skin and genital malformations. All these anomalies in the developing organism due to prenatal alcohol exposure are categorised as the foetal alcohol spectrum disorder (FASD).

\section{Effects of alcohol exposure during lactation}

The effects on neonates exposed to alcohol via breast milk are very different from the effects of in utero exposure (9). Next to an altered milk taste and smell, consumption of low to moderate amounts of alcohol can result in a reduced amount of milk produced without altering its quality $(18,19)$. The presence of even small amounts of alcohol in the breast milk (e.g. the mother drank 1 glass and breastfed her baby one hour later) can disrupt sleep-wake behavioural patterning of the infant (20). Regular, at least daily alcohol use during lactation can result in a retardation of motor development, not mental development (21). On a longer term, research revealed that it can even affect the hedonic response to the smell of alcohol of children aged 3 to 6: the emotional context in which parents experience alcohol and how often parents drink, influenced children's liking the odour of alcohol. Children of a parent or parents who drank alcohol to escape problems were more likely to judge the odour of beer as unpleasant than were similarly aged children whose parents did not drink to escape (22).

Alcohol intake by pregnant women in Belgium: a prospective study

215 women were included with a mean age of $29.0 \pm 4$ years and $48.1 \%$ were nulliparae. Seven percent of them were smoking at the start of the study. Prenatal nutritional supplements were used by $84.1 \%$ of the women. Mean birth weight was $3.425 \pm 0.453 \mathrm{~kg}$ and mean total gestational weight gain was $11.8 \pm 6.5 \mathrm{~kg}$.

Total abstinence of alcohol was seen in $76 \%$ of the women (Figure 1). Of the $24 \%$ of women who consumed any alcohol, 13.9\% consumed alcohol during 1 of the 3 weeks. These women were considered to be low consumers. Five women $(2.5 \%)$ reported drinking during all 3 weeks of recording. This could suggest that these women drink more regularly.

Binge drinking, defined as drinking more than $50 \mathrm{~g}$ on one occasion (6) was not recorded. However, one woman reported a consumption of $31 \mathrm{~g}$ in 1 evening and a second women $36 \mathrm{~g}$ during an afternoon party. The highest consumption levels during the $1 \mathrm{st}, 2 \mathrm{nd}$ and $3 \mathrm{rd}$ tri- 
mester were $60 \mathrm{~g} /$ week, $63 \mathrm{~g} /$ week and $70 \mathrm{~g} /$ week respectively, reported by 3 different women. This was never consumed on one occasion, but spread over three or four consecutive days. The woman drinking $60 \mathrm{~g} /$ week during the 1 st trimester drank 1 beer ( $6 \%$ alcohol) on Thursday, another beer $(6 \%$ alcohol) and a glass of wine on Friday and 3 glasses of wine on Saturday. The woman with the highest alcohol level during the 2nd trimester drank 2 beers on Saturday and 1 liquor and 2 glasses of wine on Sunday. She also drank during the first and third trimester of her pregnancy: 2 glasses on 1 day per week during the 1 st trimester and 1 glass of wine on Monday, 2 glasses of wine on Thursday and 1 beer on Saturday during the 3rd trimester. During the 3rd trimester, the highest alcohol intake in 1 week was spread over 4 consecutive days and consisted of wine and sparkling wine.

Figure 1. Percentage of pregnant women consuming no, 1, 2 , or $\geq 3$ standard alcoholic consumptions during the recorded weeks in our study

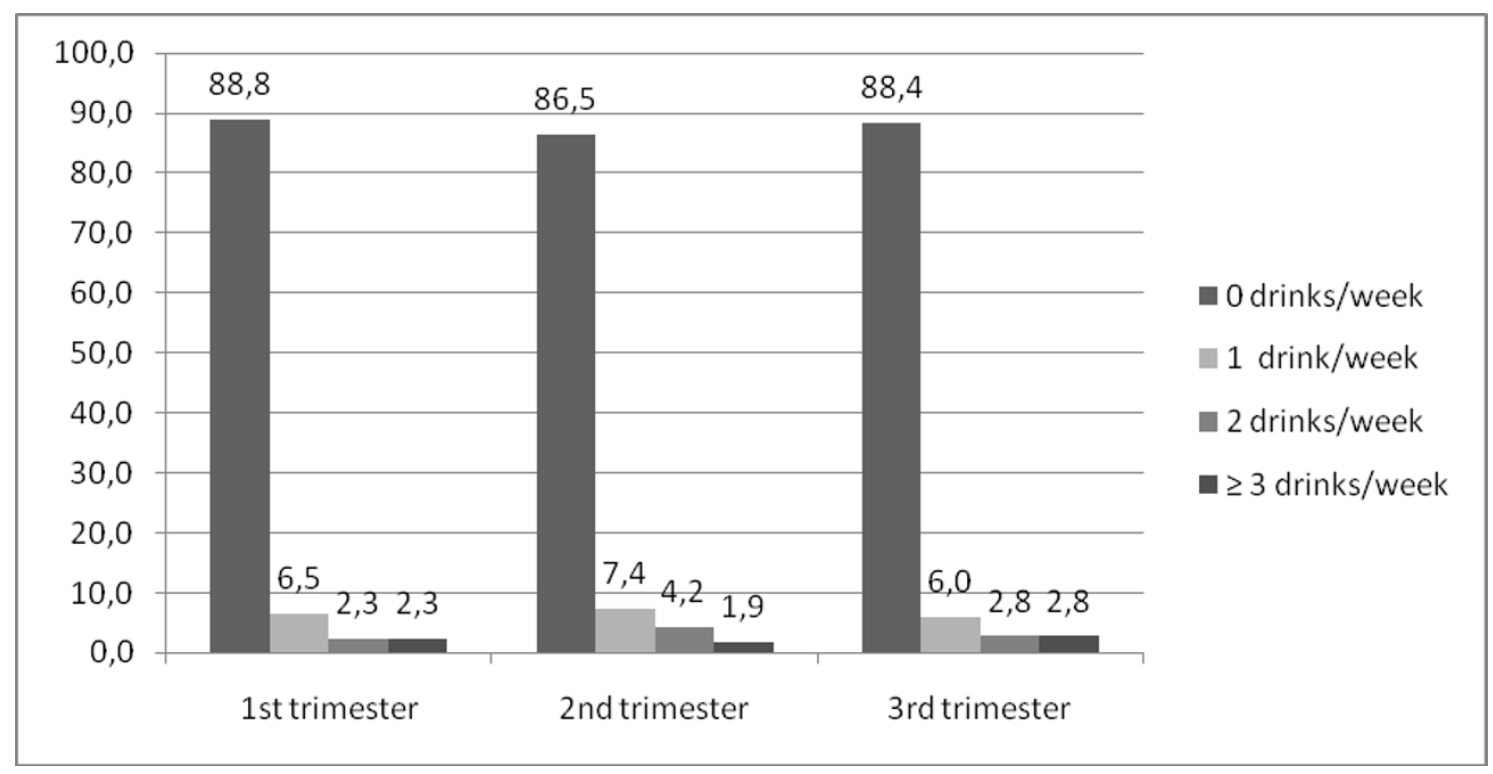

A significant positive correlation was found between the total alcohol consumed and age $(r=0.267, p=0.000)$. No correlation between alcohol and BMI, parity, smoking, gestational weight gain or birth weight could be observed.

\section{Discussion}

Recently, the Belgian Superior Health Council published a report recommending total abstinence from alcohol for women of reproductive age in the prepregnancy period, during pregnancy and during lactation (9). The American Academy of Pediatrics (AAP) and the American College of Obstetricians and Gynecologists (ACOG) issue the same recommendations for both pregnant and preconceptional women (23). This recommendation is very strict and severe, but one must look at the total context: firstly, no safe threshold for consumption has been identified and in utero alcohol exposure of the foetus can be associated with a wide range of anomalies which can persist during childhood, puberty and even adulthood. Sec- 
ondly, women who consume or continue consuming alcohol during pregnancy tend to be older (24) and already have an increased risk for adverse pregnancy outcome (25) and are often poly-substance-users $(26,27)$. In our prospective study, alcohol consumption was also related to increasing maternal age. Similar rates of substance use during pregnancy by women of different racial, social class and age categories were reported (28). However, other more tolerant recommendations also exist. The Australian National Health and Medical Research Council for instance recommends that 'if women who are pregnant or might soon become pregnant and choose to drink, over a week, should have less than 7 standard drinks, and, on any one day, no more than 2 standard drinks' (29). The current UK Department of Health guidelines recommend that women who are trying to become pregnant or are at any stage of pregnancy, should not drink more than 1 or 2 units of alcohol once or twice a week, and should avoid episodes of intoxication (30). Obstetricians point out that with a strict alcohol policy the situation where a woman who had a few drinks in the pre-recognised part of her pregnancy and is now worried that she seriously damaged her baby can become problematic. This is a realistic remark since approximately one quarter of the women reported binge drinking at least once, mostly in the pre-recognised part of pregnancy (31). Binge drinking in the pre-recognised part of pregnancy was more common among women aged 2529 years, who were nulliparous, well educated, having good jobs or being skilled workers (31). In our study $11.2 \%$ of the women also reported drinking low to moderate amounts of alcohol in their first trimester. It is extremely important to avoid panic among these women to prevent anxiety and unnecessary abortions. After all, the effects of in utero exposure to alcohol can vary in function of the total amount of alcohol consumed, the pattern of alcohol consumption (e.g. binge drinking or chronic exposure), the developing stage of the embryo or foetus, maternal health and nutritional status, the presence of polysubstance use (e.g. smoking, drugs), the maternal capacity to metabolise alcohol and the individual sensitivity of the unborn child (9). However, to abstain from drinking at any point in pregnancy is the best for both mother and child.

Even though the general public has knowledge of the toxic effects of alcohol during pregnancy and lactation, and questions about alcohol consumption are part of the standard anamnesis at booking (32), total abstinence is no reality. Numbers on prevalence of alcohol use during pregnancy range from $12.3 \%$ up to $23 \%(5,7)$. In our prospective study, one in four of the pregnant women report alcohol use. One should notice that the prevalence numbers in this and all other studies previously mentioned are based on maternal self-reports which is a major limitation. People often do not recall the amount and frequency of their alcohol intake, which results in an underestimation of real intake. Furthermore, pregnant women underreport their alcohol use, especially if they drink heavily, because they fear being stigmatised (33). Another limitation of our study is the use of 7-day food records, recording intake during a short period of time. Testing blood and core blood, breath or urine for alcohol is only useful for assessing very recent alcohol exposure, but no laboratory test is able to identify and quantify prenatal alcohol use over a longer period, or to distinguish a single drinking episode from chronic, intermittent alcohol use (33). This methodological problem 
clearly leads to an underestimation of the alcohol use among pregnant women. The use of screening tools can significantly assist clinicians in accurately identifying women who consume alcohol during pregnancy (34). Unfortunately, less than one quarter of the obstetricians who do ask about alcohol use, use a standardised screening tool (32). A possible barrier could be lack of time. However, the T-ACE is a brief questionnaire specifically designed to detect alcohol use among pregnant women which consists of only 4 questions and takes less than 1 minute to complete (35). Other barriers can include patient sensitivity, lack of confidence in skills and inadequate referral sources (23).

In summary, at least $25 \%$ of pregnant women still consumes alcohol even though recommendations for total abstinence are made. If women of reproductive age and pregnant women would totally abstain from alcohol, serious, long-lasting consequences could be prevented.

\section{Acknowledgements}

I. Guelinckx was supported by a doctoral scholarship from the DANONE INSTITUTE Belgium. R. Devlieger is recipient of a clinical research grant from the University Hospital Gasthuisberg, Leuven (2007-2010).

\section{References}

1. WIV. Gezondheidsenquête door middel van Interview, België, 2004. D/2006/2505/4, EPI-Report 2006-35

2. Smart RG, Adlaf EM, Knoke D. Use of the CAGE scale in a population survey of drinking. J Stud Alcohol 1991;52(6):593-6

3. Nayak RB, Murthy P. Fetal alcohol spectrum disorder. Indian Pediatr 2008;45(12):977-83

4. US Centers for Disease Control and Prevention. Alcohol use among women of childbearing age-United States, 1991-1999. Mor Mortal Wkly Rep CDC Surveill Summ 2002;51:273-6

5. Denny $\mathrm{CH}$, US Centers for Disease Control and Prevention. Pattern of alcohol use since 1991 remains unchanged among pregnant women. Mor Mortal Wkly Rep CDC Surveill Summ 2009;58:529-32

6. O'Leary CM, Nassar N, Kurinczuk JJ, Bower C. The effect of maternal alcohol consumption on fetal growth and preterm birth. BJOG 2009;116(3):390-400

7. Goransson M, Magnusson A, Bergman H, Rydberg U, Heilig M. Fetus at risk: prevalence of alcohol consumption during pregnancy estimated with a simple screening method in Swedish antenatal clinics. Addiction 2003;98(11):1513-20

8. Sayal K, Heron J, Golding J, Alati R, Smith GD, Gray R, et al. Binge pattern of alcohol consumption during pregnancy and childhood mental health outcomes: longitudinal population-based study. Pediatrics 2009;123(2):e289-96

9. Hoge Gezondheidsraad. Risico's van alcoholgebruik tijdens de zwangerschap en de borstvoedingsperiode. 8462 March 2009. https://portal.health.fgov.be/portal/page?_pageid=56,512429\&_dad=portal\&_schema=PORTAL

10. Wester-Gandy J, Madden A, Holdsworth M. Oxford Handbood of Nutrition and Dietetics. New York: Oxford University Press; 2006

11. Lawton ME. Alcohol in breast milk. Aust N Z J Obstet Gynaecol 1985;25(1):71-3

12. Jaddoe VW, Bakker R, Hofman A, Mackenbach JP, Moll HA, Steegers EA, et al. Moderate alcohol consumption during pregnancy and the risk of low birth weight and preterm birth. The generation $\mathrm{R}$ study. Ann Epidemiol 2007;17(10):834-40 
13. Streissguth AP, Barr HM, Sampson PD. Moderate prenatal alcohol exposure: effects on child IQ and learning problems at age 7 1/2 years. Alcohol Clin Exp Res 1990;14(5):662-9

14. Windham GC, Fenster L, Hopkins B, Swan SH. The association of moderate maternal and paternal alcohol consumption with birthweight and gestational age. Epidemiology 1995;6(6):591-7

15. Burd L, Carlson C, Kerbeshian J. Fetal alcohol spectrum disorders and mental illness. Special issue on neuropsychological effects of alcohol use and misuse. Int J Disabil Human Dev 2007;6:383-96

16. Stratton K, Howe C, Battaglia FC, Institute of Medicine. Fetal Alcohol Syndrome: Diagnosis, Epidemiology, Prevention, and Treatment. Washington, DC: National Academy Press; 1996

17. Centers for Disease Control and Prevention (CDC). Fetal alcohol syndrome Alaska, Arizona, Colorado, and New York, 1995-1997. MMWR Morb Mortal Wkly Rep 2002;51(20):433-5

18. Lowdermilk DL, Bobak IM, Perry SE. Maternity \& Women's Health Care. St. Louis: Mosby Inc; 1997

19. Mennella JA. Infants' suckling responses to the flavor of alcohol in mothers' milk. Alcohol Clin Exp Res 1997;21(4):581-5

20. Mennella JA, Garcia-Gomez PL. Sleep disturbances after acute exposure to alcohol in mothers' milk. Alcohol 2001;25(3):153-8

21. Little RE, Anderson KW, Ervin $\mathrm{CH}$, Worthington-Roberts $\mathrm{B}$, Clarren SK. Maternal alcohol use during breast-feeding and infant mental and motor development at one year. N Engl J Med 1989;321(7):425-30

22. Mennella JA, Garcia PL. Children's hedonic response to the smell of alcohol: effects of parental drinking habits. Alcohol Clin Exp Res 2000;24(8):1167-71

23. Bailey BA, Sokol RJ. Pregnancy and alcohol use: evidence and recommendations for prenatal care. Clin Obstet Gynecol 2008;51(2):436-44

24. Day NL, Cottreau CM, Richardson GA. The epidemiology of alcohol, marijuana, and cocaine use among women of childbearing age and pregnant women. Clin Obstet Gynecol 1993;36(2):232-45

25. Jahan MK, Shafiquzzaman M, Nahar K, Rahman M, Sultana N, Rahman MM, et al. Outcome of pregnancy in women 35 years of age and above. Mymensingh Med J 2009;18(1):7-12

26. Mayet S, Groshkova T, Morgan L, MacCormack T, Strang J. Drugs, alcohol and pregnant womenchanging characteristics of women engaging with a specialist perinatal outreach addictions service. Drug Alcohol Rev 2008;27(5):490-6

27. Odendaal HJ, Steyn DW, Elliott A, Burd L. Combined effects of cigarette smoking and alcohol consumption on perinatal outcome. Gynecol Obstet Invest 2009;67(1):1-8

28. Hans SL. Demographic and psychosocial characteristics of substance-abusing pregnant women. Clin Perinatol 1999;26(1):55-74

29. National Health and Medical Research Council. Australian Alcohol Guidelines: Health risks and Benefits: Canberra: NHMRC; 2001

30. Department of Health. The Pregnancy Book. London: The Stationery Office; 2005

31. Strandberg-Larsen K, Rod Nielsen N, Nybo Andersen AM, Olsen J, Gronbaek M. Characteristics of women who binge drink before and after they become aware of their pregnancy. Eur $\mathrm{J}$ Epidemiol 2008;23(8):565-72

32. Diekman ST, Floyd RL, Decoufle P, Schulkin J, Ebrahim SH, Sokol RJ. A survey of obstetriciangynecologists on their patients' alcohol use during pregnancy. Obstet Gynecol 2000;95(5):756-63

33. Littner $\mathrm{Y}$, Bearer CF. Detection of alcohol consumption during pregnancy--current and future biomarkers. Neurosci Biobehav Rev 2007;31(2):261-9

34. Russell M, Martier SS, Sokol RJ, Mudar P, Bottoms S, Jacobson S, et al. Screening for pregnancy riskdrinking. Alcohol Clin Exp Res 1994;18(5):1156-61

35. Sokol RJ, Martier SS, Ager JW. The T-ACE questions: practical prenatal detection of risk-drinking. Am J Obstet Gynecol 1989 Apr;160(4):863-8; discussion 8-70

36. Wester-Gandy J, Madden A, Holdsworth M. Oxford Handbook of Nutrition and Dietetics. Oxford University Press; 2006 